The Experience of Music in Congenital Amusia

Author(s): Diana Omigie, Daniel Müllensiefen and Lauren Stewart

Source: Music Perception: An Interdisciplinary Journal, Vol. 30, No. 1 (September 2012), pp.

$1-18$

Published by: University of California Press

Stable URL: http://www.jstor.org/stable/10.1525/mp.2012.30.1.1

Accessed: 19/03/2014 15:36

Your use of the JSTOR archive indicates your acceptance of the Terms \& Conditions of Use, available at

http://www.jstor.org/page/info/about/policies/terms.jsp

JSTOR is a not-for-profit service that helps scholars, researchers, and students discover, use, and build upon a wide range of content in a trusted digital archive. We use information technology and tools to increase productivity and facilitate new forms of scholarship. For more information about JSTOR, please contact support@jstor.org. 


\section{The Experience of Music in Congenital Amusia}

\author{
Diana Omigie, Daniel Müllensiefen, \\ \& LAUREN STEWART \\ University of London, New Cross, London, \\ United Kingdom
}

INDIVIDUALS WITH CONGENITAL AMUSIA HAVE DIFFICULTY recognizing and discriminating melodies. While much research has focused on the perceptual deficits of congenital amusics, the extent to which these deficits have an impact on the ability to engage with and appreciate music remains unexplored. The current study used experience sampling methodology to identify distinct patterns of music-related behavior in individuals with amusia and matched controls. Cluster analysis was used to group individuals according to the similarity of their behavior, regardless of their status as amusic or control. This yielded a two-cluster solution: one cluster comprising 59\% of the amusic sample and 6\% of controls and the other comprising $41 \%$ of the amusic sample and $94 \%$ of controls. Comparisons of the two clusters in terms of specific aspects of music listening behavior revealed differences in levels of music engagement and appreciation. Further comparisons provided support for the existence of amusic subgroups showing distinct attitudes toward music. The findings are discussed in relation to social, contextual, and demographic factors.

Received January 31, 2011, accepted September 6, 2011.

Key words: congenital amusia, music engagement and appreciation, music perception, experience sampling methodology, cluster analysis

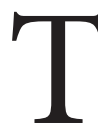
The ObServation that OTHERWISE NORMally developed individuals can lack basic musical abilities was first reported over a hundred years ago (Allen, 1878). The term congenital amusia (amusia, hereafter), however, was first coined less than a decade ago (Ayotte, Peretz, \& Hyde, 2002). Used to describe individuals born with a lifelong musical impairment, empirical work into the condition has confirmed that amusia is a genuine perceptual agnosia, characterized by deficits in melody recognition and discrimination (Stewart, von Kriegstein, Warren, \& Griffiths, 2006). Neuroimaging studies have suggested that the musical difficulties observed in individuals with amusia are related to subtle differences in brain structure and connectivity (Hyde, Zatorre, Griffiths, Lerch, \& Peretz, 2006; Loui, Alsop, \& Schlaug, 2009; Mandell, Schulze, \& Schlaug, 2007) and the condition appears to be hereditary (Drayna, Manichaikul, de Lange, Snieder, \& Spector, 2001; Peretz, Cummings, \& Dubé, 2007).

The condition of amusia is ascertained using a standardized diagnostic tool known as the Montreal Battery for the Evaluation of Amusia (MBEA; Peretz, Champod, \& Hyde, 2003). The MBEA is composed of six subtests of thirty trials each. Each subtest assesses distinct aspects of music processing. In a typical trial, participants are required to discriminate between pairs of novel melodies, which may or may not differ at a single point. Using this battery, a systematic appraisal of participants' perception of pitch organization (scale, contour, and interval), temporal organization (rhythm and meter), and memory for melodies is made.

Previous research has shown that amusia is characterized by poor musical perception, particularly on the pitchbased subtests of the MBEA (scale, contour, and interval) while performance on the rhythm test shows greater heterogeneity but can be in the normal range (Peretz et al., 2003). For this reason, the majority of research into congenital amusia has investigated pitch-related processing, with findings indicating elevated thresholds in pitch change detection, pitch direction discrimination, and poor memory for pitch information (Foxton, Dean, Gee, Peretz, \& Griffiths, 2004; Gosselin, Jolicoeur, \& Peretz, 2009; Hyde \& Peretz, 2004; Peretz et al., 2002; Tillmann, Schulze, \& Foxton, 2009; Williamson, McDonald, Deutsch, Griffiths, \& Stewart, 2010). Poor memory for timbral attributes has also been implicated although this deficit appears to be less severe compared to the pitch dimension (Tillmann et al., 2009).

While behavioral testing has typically been concerned with characterizing the perceptual nature of congenital amusia, little attention has been paid to the impact of disordered musical perception on the everyday uses and appreciation of music. At least two alternative scenarios

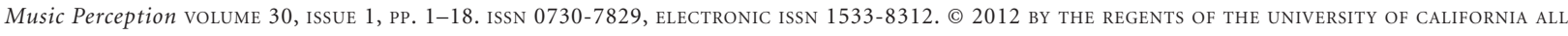
RIGHTS RESERVED. PLEASE DIRECT ALL REQUESTS FOR PERMISSION TO PHOTOCOPY OR REPRODUCE ARTICLE CONTENT THROUGH THE UNIVERSITY OF CALIFORNIA PRESS'S RIGHTS AND PERMISSIONS WEBSITE, HTTP://WWW.UCPRESSJOURNALS.COM/REPRINTINFO.ASP.DOI: 10.1525/MP.2012.30.1.1 
might be anticipated regarding the extent to which congenital amusia may impact on engagement with music in these individuals. In one scenario, if engagement and appreciation of music are dependent upon the listener having an intact representation of its intrinsic features, then we would expect that individuals with amusia would be unable to fully engage with and appreciate music. Cochlear implant users constitute one group of individuals for whom an impoverished perception of music's intrinsic features results in a negative impact on levels of music appreciation (e.g., Gfeller, Christ, Knutson, Witt, \& Mehr, 2003; Leal et al., 2003). Due to limitations in the current state of technology, the cochlear implant device is constrained in its ability to code the spectrum of sound needed to perceive pitch and timbre (Galvin, Fu, \& Nogaki, 2007; Sucher \& McDermott, 2007). Not surprisingly, some cochlear implant users describe music as "hard to follow" and rate the sound of musical instruments as "emptier" than they would have expected a normal hearing listener to have perceived it (Gfeller, Witt, Woodworth, Mehr, \& Knutson, 2002; Gfeller et al., 2003). In line with the suggestion that impaired perception may be a limiting factor in the appreciation of musical sound, several amusic individuals report difficulty in making sense of their perceptual experience. One individual says:

I know that [music] is respected and loved by many but I just cannot get the point. I do not see what enthuses people or why it is so pleasurable.

Growing up in the 60's, I did learn lyrics and tunes but could never hold the tunes... I can remember lyrics as poems, and whilst I can appreciate the words, the tunes leave me thinking 'what is that all about...?' (J.S., personal communication, 9/1/2007).

On the other hand, it may be that engagement and appreciation of music can emerge from factors that are extrinsic to the music itself. Sociological, psychological, and ethnographic research emphasizes music's many different affordances in aspects of our personal lives, our social lives, and at different stages of our maturity. Young listeners may exploit specific types of music to construct a sense of self, communicating their values and beliefs through their musical preferences while older listeners may use the music of their youth to evoke memories and maintain a sense of identity even as the need for impression management wanes (MacDonald, Hargreaves, \& Miell, 2002; North \& Hargreaves, 1999; Zillmann \& Gan, 1997). DeNora (2000) describes the widespread use of music as a way of “organizing one's internal and social world, helping to continually reconstruct the aims of various activities" and provides multiple real-life examples of music's various roles, from creating a personal sound environment to managing social situations while Small (1998) coins the term "musicking" to describe music as something that is done and taken part in, rather than an abstract art to be contemplated. According to this view, inaccurate perception of music's intrinsic features, as occurs in amusia, would not necessarily prevent engagement and appreciation of music. Small further describes the widespread phenomenon of audience members "sharing with strangers" at musical performances and the "underlying kinship" that exists between them even though they do not speak. Furthermore, a plethora of literature from different disciplines further emphasizes music's power to create feelings of belonging in its listeners (Hays \& Minchiello, 2005; Russell, 1997). Thus, it is presently unclear whether perceptual deficits, as seen in amusia, can be expected to impact upon the engagement with and appreciation of music and addressing this question empirically was the focus of the present study.

A previous study provides information on this question. In order to investigate the uses and importance of music in the everyday lives of a group of individuals with amusia, McDonald and Stewart (2008) used a questionnaire study, probing the situations in which amusics individuals used music, the psychological functions they attributed to music, and their feelings about music in public places. The results showed that, in general, amusic individuals did not incorporate music into their lives to the same extent as matched controls. Moreover, music did not seem to fulfill psychological functions (such as matching or changing mood; evoking memories of past people and places) to the same degree. Nevertheless, the authors found a wide range of profiles within the sample of amusic individuals they evaluated, with a subgroup proving indistinguishable from the controls in these respects.

While informative, the authors' questionnaire study was limited in the level of detail it provided. The study neither afforded the opportunity to probe individual instances of musical listening, nor captured the possible mediating effects of situation and company, both of which may be important factors in the use and experience of music (North, Hargreaves, \& Hargreaves, 2004). Experience Sampling Methodology (ESM; Larson \& Csikszentmihalyi, 1983) allows collection of data on the uses, functions, and effects of music, as well as detailed information on the different contextual factors that may influence listeners' reactions and behavior. Data from ESM can be summarized quantitatively, which lends it to statistical analysis. 
The technique, which involves contacting participants in the "stream of everyday life" (Konecni, 1982) and prompting them to complete pre-prepared diary forms relating to their experience of music at that point in time, offers a degree of ecological validity that is lacking from retrospective reports while maintaining a systematic framework that allows experiences and listening behaviors to be evaluated and compared.

Sloboda and colleagues (2001) demonstrated the value of the ESM approach for probing the uses and importance of music in every day life in a seminal study focusing on a small sample of individuals (Sloboda, O'Neill, \& Ivaldi, 2001). Subsequently, North and colleagues used the same methodology on a much larger sample of individuals. They were able to demonstrate how ubiquitous music is in the general population (North et al., 2004). Typical listeners in the study reported a high incidence of exposure to music - often, though not always, as a result of consciously incorporating it into a range of everyday activities (from driving to bathing) and with the aim of achieving various psychological states. Results further demonstrated that effects of music on a listener and the levels of engagement and appreciation they exhibited depended on a range of factors including the degree of control the listener had over the music being heard, the situation in which the music was heard, and whether or not the listening episode occurred in the presence or absence of others.

The present study used an ESM approach with a group of individuals with amusia and a group of controls matched on age, gender and years of music training to address the question of whether individuals with amusia engage with music differently in everyday life compared to typical listeners and the extent to which this is mediated by contextual factors such as situation and company. A questionnaire based on that used by North and colleagues (2004) probed details concerning the frequency of exposure to music, the frequency of choosing to listen to music, and the subjective levels of liking and attention reported by amusic and control individuals. These profiles also included information on the frequency of reporting different reasons for listening (if chosen) and effects of listening (if not chosen) as well as what the participant was doing and who they were with during ESM episodes in which music was heard.

In order to make full use of the rich dataset afforded by the current ESM approach, data incorporating information on all variables were obtained and summarized into profiles for each individual. Cluster analysis allowed grouping of individuals, regardless of their status as amusic or control, according to the similarity of their profiles. Once a grouping solution was found, the composition of groups in terms of individuals (amusic versus controls) could then be established, followed by posthoc testing to probe which facets of musical behavior differed between the groups that were identified as dissimilar. In this way, the method initially determined whether individuals with amusia are similar or different compared with non-amusics while subsequent tests described the precise ways in which they differed.

\section{Method}

\section{PARTICIPANTS}

Seventeen individuals with amusia and 17 controls matched for age, gender, and music training participated in the study. They were recruited via an online assessment based on the scale subtest of the Montreal Battery of Evaluation of Amusia (MBEA; Peretz et al., 2003, www.delosis.com/listening/home.html). Participants who had taken the online scale test at least twice and achieved a score of 22/30 or less (Peretz et al., 2003) on both occasions, were invited to the laboratory where four of the six subtests of the MBEA were run in a sound attenuated booth (scale, contour, interval, and rhythm subtests). Previous research has shown that amusia is characterized by poor perception in the pitch-based subtests of the MBEA (scale, contour, and interval) while only half of them typically show a deficit in the rhythm subtest (Peretz et al., 2003). Thus, a composite score was calculated for the three pitch-based subtests, using 65 as a cut off score. Individuals were classified as amusic if their composite score fell below this value (Peretz et al., 2003). During a screening interview carried out when they first came to the lab to be tested, all participants classified as amusic additionally reported lifelong difficulties with music: participants mentioned their difficulties with singing in tune (as remarked upon by friends and family), inability to recognize familiar tunes or summon them from memory, and difficulty in spotting "out of key" notes. During the study, a comparable proportion of participants were involved in full time employment in the two groups (70\%). Table 1 provides background information on the amusic and control groups, while Table 2 provides demographic and individual scores on the MBEA subtests.

\section{THE EXPERIENCE SAMPLING DIARY}

Each participant was provided with a compact and portable diary, allowing them to detail information about their experience of music in their environment when contacted. Participants were required to fill in one sheet every time they received a text message on their mobile phone. 
TABLE 1. Summary of Participant Background Characteristics Showing Descriptive Statistics of Age, Gender, and Years of Music Training, and Mann-Whitney U Comparisons.

\begin{tabular}{lllll}
\hline & & Age & Gender & $\begin{array}{c}\text { Years of Music } \\
\text { Training }\end{array}$ \\
\hline Amusic & Mean & 45.65 & $5 \mathrm{M}, 12 \mathrm{~F}$ & 0.97 \\
& $S D$ & 12.08 & & 1.94 \\
& Range & $21-62$ & & $0-7$ \\
Control & Mean & 45.06 & $5 \mathrm{M}, 12 \mathrm{~F}$ & 1.88 \\
& SD & 12.24 & & 3.08 \\
& Range & $22-63$ & & $0-10$ \\
& $U$ & 152.5 & & 128.0 \\
& $P$ & .80 & & .53 \\
\hline
\end{tabular}

Each sheet contained roughly 10 items that pilot testing had shown took less than a minute to complete. The initial section on each diary sheet asked for information about the date and time that the text message was received, the time when the sheet was completed and whether or not music could be heard. The subsequent items were only relevant if music could be heard. Following North and colleagues (2004), participants were probed on the following aspects of their music listening behavior: whether the participant was alone (yes/no) and whether they had chosen to hear the music (yes/no). Episodes where music was heard were probed concerning reasons for listening (if self-chosen), effects of the music (if not self-chosen), degree of liking and attention, and ongoing activities (respondents were required to circle from a list of items including housework, getting dressed, and bathing). Details about the genre of music were also requested (see Appendix 1 for a sample sheet of the diary).

\section{PROCEDURE}

All participants completed and returned written consent forms to participate in the research, which was reviewed and approved by the Goldsmiths, University of London Ethics Committee.

Diaries were sent out to all participants along with a detailed instruction sheet explaining what was required of them. Participants were requested to keep the diaries with them at all times for the duration of the study and to fill in one sheet of the diary as soon as possible after receiving a text message, noting the time at which the entry was made.

Over the duration of the week-long study, participants were contacted by text message using an online messaging service (http://www.fastsms.co.uk/). They were sent

TABLE 2. Demographic Details and Individual MBEA Subtest Scores for Amusic Participants and Performance of Controls on Scale Subtests.

\begin{tabular}{|c|c|c|c|c|c|c|c|c|c|c|c|c|c|c|c|c|c|}
\hline AMUSICS & A1 & A2 & A3 & A4 & A5 & A6 & A7 & A 8 & A9 & A10 & A11 & A12 & A13 & A14 & A15 & A16 & A17 \\
\hline \multicolumn{18}{|l|}{ Demographics } \\
\hline Gender & $\mathrm{F}$ & $\mathrm{M}$ & M & $\mathrm{F}$ & $\mathrm{M}$ & M & $\mathrm{F}$ & $\mathrm{F}$ & M & $\mathrm{F}$ & $\mathrm{F}$ & $\mathrm{F}$ & $\mathrm{F}$ & $\mathrm{F}$ & $\mathrm{F}$ & $\mathrm{F}$ & $\mathrm{F}$ \\
\hline Age & 28 & 32 & 35 & 38 & 38 & 48 & 48 & 54 & 56 & 56 & 56 & 57 & 57 & 62 & 39 & 21 & 51 \\
\hline Education & 18 & 16 & 13 & 16 & 20 & 11 & 13 & 14 & 16 & 16 & 16 & 20 & 17 & 17 & 11 & 13 & 20 \\
\hline Music training & 0.5 & 0 & 0 & 0 & 0 & 0 & 0 & 1 & 0 & 0 & 0 & 3 & 0 & 0 & 1 & 7 & 4 \\
\hline \multicolumn{18}{|l|}{$M B E A$} \\
\hline Scale & 17 & 20 & 14 & 20 & 18 & 21 & 17 & 23 & 18 & 23 & 16 & 19 & 19 & 23 & 17 & 23 & 20 \\
\hline Contour & 15 & 22 & 15 & 22 & 20 & 18 & 24 & 16 & 21 & 20 & 14 & 23 & 19 & 23 & 25 & 23 & 20 \\
\hline Interval & 17 & 19 & 14 & 22 & 18 & 18 & 24 & 17 & 16 & 19 & 16 & 18 & 16 & 18 & 20 & 17 & 21 \\
\hline Composite & 49 & 61 & 43 & 64 & 56 & 57 & 65 & 56 & 55 & 62 & 46 & 60 & 54 & 64 & 62 & 63 & 61 \\
\hline Rhythm & 19 & 25 & 18 & 23 & 14 & 24 & 29 & 23 & 20 & 29 & 24 & 27 & 21 & 28 & 27 & 24 & 22 \\
\hline CONTROLS & $\mathrm{C} 1$ & $\mathrm{C} 2$ & $\mathrm{C} 3$ & $\mathrm{C} 4$ & $\mathrm{C} 5$ & C6 & $\mathrm{C} 7$ & $\mathrm{C} 8$ & C9 & C10 & C11 & C12 & C13 & C14 & C15 & C16 & C17 \\
\hline Gender & $\mathrm{F}$ & M & M & $\mathrm{F}$ & $\mathrm{M}$ & M & $\mathrm{F}$ & $\mathrm{F}$ & M & $\mathrm{F}$ & $\mathrm{F}$ & $\mathrm{F}$ & $\mathrm{F}$ & $\mathrm{F}$ & $\mathrm{F}$ & $\mathrm{F}$ & $\mathrm{F}$ \\
\hline Age & 28 & 28 & 37 & 34 & 38 & 47 & 52 & 50 & 57 & 53 & 54 & 63 & 54 & 60 & 39 & 22 & 50 \\
\hline Music training & 8 & 0 & 0 & 0 & 0 & 0 & 0 & 1 & 0 & 2 & 0 & 0 & 0 & 3 & 3 & 10 & 5 \\
\hline Scale test 1 & 27 & 26 & 29 & 28 & 26 & 28 & 26 & 27 & 25 & 26 & 27 & 27 & 27 & 26 & 26 & 30 & 27 \\
\hline Scale test 2 & 28 & 27 & 30 & 29 & 30 & 29 & 26 & 28 & 26 & 28 & - & - & 28 & 27 & 28 & 30 & 29 \\
\hline Average & 27.5 & 26.7 & 29.5 & 28.5 & 29 & 28.5 & 26 & 27.5 & 25.5 & 27 & 27 & 27 & 27.5 & 26.5 & 27 & 30 & 28 \\
\hline
\end{tabular}


six text messages a day for seven days between the hours of 8:00 a.m. and 11:00 p.m. The six text messages sent to each participant were spread out across the time window to sample twice, on average, from different parts of the day (morning, afternoon, evening) while varying the exact times from day-to-day to avoid predictability. Exact times differed across participants but were balanced between groups. At the end of the study, participants returned the diaries using pre-stamped/addressed envelopes. They were awarded a small token of gratitude for their participation.

\section{Analysis}

\section{DATA PRE-PROCESSING}

All items in the paper ESM diaries were coded and entered into an electronic spreadsheet. Participants showed a high compliance rate with $98.80 \%$ (1,411 out of 1,428 ) of all forms completed in total. Of these $73.14 \%$ $(1,032)$ were completed within $10 \mathrm{~min}$ of receiving the text message. No difference was found between controls $(M=17: 39)$ and amusic $(M=16: 99)$ participants regarding the delay between receiving the text message and responding to it, $t(32)=0.07, p=.94$. For the purposes of reliability, a limit of three hrs was chosen as the longest acceptable delay. This qualified for further analysis a total of 705 (amusics) and 670 episodes (controls). Of these, $166(23.50 \%)$ and 294 (43.90\%) were listening episodes (diary entries where music was reported to be present) for each respective group. Details for each listening episode were coded into two formats: Yes/ No responses representing binary judgments (e.g., music chosen or not, listening alone or not, listening to pass the time or not, etc.) and numeric scores on a Likert rating scale (1 to 10) representing listeners' reported psychological state (e.g., liking and attention).

\section{HIERARCHICAL CLUSTER ANALYSIS}

To make full use of this rich dataset, a multivariate technique was employed to allow simultaneous consideration of multiple variables. A cluster analysis groups objects into subsets such that objects in subsets are similar to each other but dissimilar to members of the other subsets (Everitt, 1974). Agglomerative hierarchical clustering, the specific type of clustering employed, started with every single object forming a single cluster and, over each successive iteration, merged the most similar pairs until all of the data was in one cluster (Everitt, 1974). In the current study, individuals were the objects merged over successive iterations, according to their similarity. One advantage of this technique is that it allowed individuals to be categorized into groups based on the multiple variables needed to satisfactorily summarize listening behavior. Another advantage of this technique was that it provided an unbiased method of identifying potential heterogeneity within the amusic and control samples.

To make the data suitable for cluster analysis, it was necessary to transform the data into a format that defined a listening profile for each of the 34 participants. Proportion variables were created from single episodes by expressing the incidence of a given observation as a proportion of the number of times the observation could possibly have been made. Thus, for each individual, the number of episodes where music was heard (listening episodes) was expressed as a proportion of the total number of times the individual made a response in the diary. Similarly, the number of listening episodes experienced with company, the number of chosen music episodes, and the number of episodes with which individuals reported different company types, were expressed as a proportion of the total number of listening episodes. The frequency of each possible reason for listening to music was expressed as a proportion of the number of times they actually chose to listen to music, while the frequency of each of the effects of listening was expressed as a proportion of the number of times they heard music without having chosen it. The degree of liking and attention was expressed as the mean rating across all music episodes experienced. In order to convert these condensed responses into a series of dimensionless quantities, each individual's value for each variable was expressed as a $z$-score with respect to the means and standard deviations of both groups combined. A log transform was first applied to all proportion variables in order to make the distribution of the proportion variables comparable to those variables that were derived by averaging Likert scores. The result of these steps was a data frame consisting of 44 standardized variables for all 34 participants (see Table 3 for a list of variables included in the analysis).

The cluster analysis was conducted in the R environment (R Development Core Team, 2009) using the stats package. A distance matrix was computed from the 34 by 44 data frame using the dist function, and specifying the euclidean distance measure. ${ }^{1}$ A hierarchical cluster analysis was then run on the resulting distance matrix using the hclust

\footnotetext{
${ }^{1}$ The euclidean distance is the most widely used distance metric for continuous variables. In this particular implementation variables were excluded from the pair-wise distance computations if they had a missing value for at least one of the two participants. Thus, the handling of many missing values was dealt with at the level of the distance computation.
} 
TABLE 3. List of Variables Included in the Cluster Analysis.

\begin{tabular}{|c|c|}
\hline $\begin{array}{l}\text { Listening \& } \\
\text { appreciation }\end{array}$ & $\begin{array}{l}\text { Music heard } \\
\text { Choice } \\
\text { Liking } \\
\text { Attention }\end{array}$ \\
\hline $\begin{array}{l}\text { Reasons for } \\
\text { listening }\end{array}$ & $\begin{array}{l}\text { To pass the time } \\
\text { Habit } \\
\text { To help me concentrate } \\
\text { To match my mood } \\
\text { To change my mood } \\
\text { To create a certain atmosphere } \\
\text { Relaxation } \\
\text { I knew those I was with would like it } \\
\text { To increase my energy } \\
\text { Catharsis } \\
\text { To remind me of past people and places }\end{array}$ \\
\hline Effects of listening & $\begin{array}{l}\text { It matched my mood } \\
\text { It positively changed my mood } \\
\text { It negatively changed my mood } \\
\text { It increased my energy } \\
\text { Relaxation } \\
\text { It reminded me of past places } \\
\text { Catharsis } \\
\text { It helped me concentrate } \\
\text { It hindered my concentration } \\
\text { It helped create the right atmosphere } \\
\text { It created the wrong atmosphere }\end{array}$ \\
\hline Activities & $\begin{array}{l}\text { Housework } \\
\text { Getting dressed } \\
\text { Having a bath } \\
\text { Travelling } \\
\text { Working } \\
\text { Studying } \\
\text { Reading a book } \\
\text { Shopping } \\
\text { Exercising } \\
\text { Socialising }\end{array}$ \\
\hline $\begin{array}{l}\text { Company \& } \\
\text { Company type }\end{array}$ & $\begin{array}{l}\text { Alone } \\
\text { Friends } \\
\text { Spouse/Partner } \\
\text { Work colleagues } \\
\text { Family members } \\
\text { Stranger } \\
\text { Boyfriend/Girlfriend }\end{array}$ \\
\hline
\end{tabular}

function, ${ }^{2}$ specifying the ward method which uses an analysis of variance approach to evaluate the distance between clusters during the agglomeration process. ${ }^{3}$

POSTHOC COMPARISONS

All means were reported $\pm S D$. Due to the unequal sample sizes and deviations from a normal distribution (Shapiro-Wilk normality tests), nonparametric tests were performed on all data. Mann-Whitney $U$, and Kruskal-Wallis tests were used for between-group comparisons and Wilcoxon signed rank tests were used for within-group comparisons. Exact significance values (as opposed to asymptotic values) were reported in all cases as recommended for smaller sample sizes (Field, 2005). Bonferroni corrections were applied for multiple comparisons. All tests were two-tailed.

\section{Results}

THE CLUSTER SOLUTION; DISTRIBUTIONS OF CONTROL AND AMUSIC PARTICIPANTS

Figure 1 shows the stages of cluster agglomeration via a dendrogram: a two-dimensional representation of the hierarchical classification process that illustrates the fusions made at each stage of the analysis.

As a criterion for choosing an optimal cluster solution, the maximal increase in cluster height was used (Everitt, 1974). This corresponded to the point at which the two-cluster structure merged to a single cluster. Thus, the two-cluster model was accepted as the optimal clustering solution for this dataset. Cluster 1 contained 11 individuals: 59\% of the amusic sample (10 individuals) and $6 \%$ of the control sample (one individual); Cluster 2 contained 23 individuals: $41 \%$ of the amusic sample (seven individuals) and $94 \%$ of controls (16 individuals). A $2 \times 2$ chi-square test revealed that this distribution of participant groups over the two

\footnotetext{
${ }^{2}$ While there are many different clustering techniques in the literature, hierarchical clustering was deemed most suitable for this dataset because of the large number of variables, the many skewed variable distributions, the zero inflated variables and the many missing values (the majority of these were due to idiosyncracies of participants' listening profiles. Some variables were irrelevant (110 values). Furthermore, lack of prediction as to how many tangible clusters could be formed with a sample of this size made kmeans clustering and similar methods that require the number of cluster to be derived as input unsuitable.

${ }^{3}$ The ward clustering method, which clusters observations according to the minimum variance within groups and the maximum variance between groups, provided us with compact spherical clusters that could be compared and contrasted.
} 


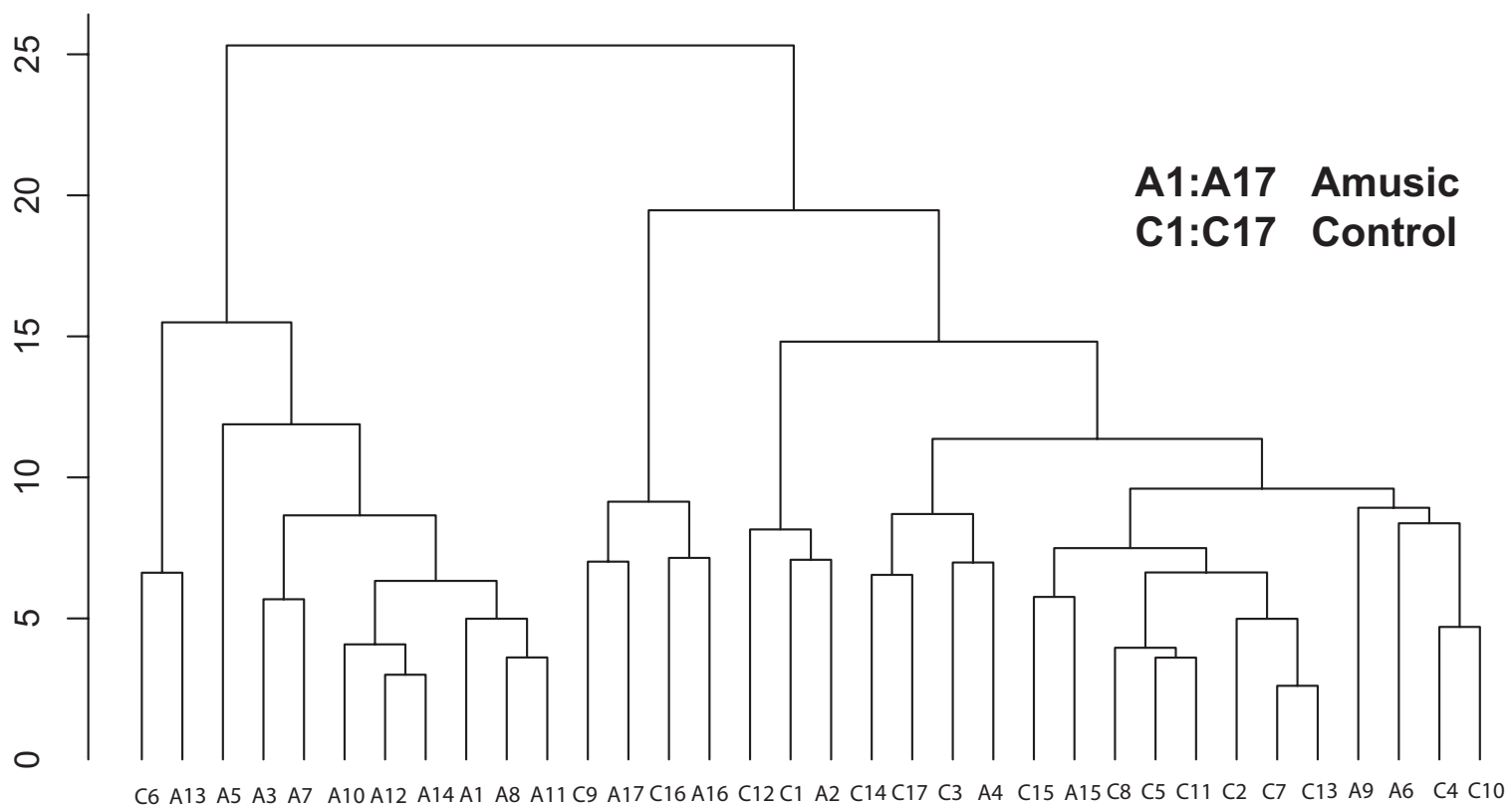

FIGURE 1. Dendrogram showing the order in which the clusters were merged. All participants are shown starting in a cluster of their own and then progressively merging to form larger clusters until all the participants are finally merged into a single group. The $y$-axis is a measure of the height at which clusters join; the larger the distance before two clusters are joined, the greater the difference between the clusters.

clusters was due to factors other than chance, $\chi(1)=$ $10.89, p<.01,{ }^{4}$ although analysis of the distribution of each group separately using binomial tests showed that this highly significant value was driven by the control group (Controls: $p=<.01$, Amusics: $p=.63$ ). There was no difference between these clusters (n clust $1=11$, $\mathrm{n}$ clust $2=23$ ) in the average time taken to respond to the text messages, $U=125.5, p=.99$.

Further analysis sought to characterize the two discrete clusters: in terms of the critical variables that described general levels of engagement (we call these key variables) and in terms of the range of reasons, effects, and activities reported (we call these summary variables).

\section{BETWEEN CLUSTER COMPARISONS: PERFORMANCE ON KEY AND SUMMARY VARIABLES}

Figure 2 shows how the two clusters differed on four key variables: how much music listeners were exposed to, how frequently they chose to hear music, reported liking to the music, and reported attention to the music. Tests of these contrasts of interest were conducted using Bonferroni adjusted alpha levels of .0125 per test (.05/4). Mann-Whitney $U$ tests revealed significant

\footnotetext{
${ }^{4}$ Further chi-square tests probing group distribution consistently revealed significant differences between the control and amusic groups in cluster solutions of up to five clusters (all $p<.01$, Bonferroni corrected).
}

differences between clusters on all four key variables: Individuals in Cluster $2(n=23)$ reported significantly more listening episodes, $M$ clust $2=41.59 \% \pm 17.36, M$ clust $1=16.75 \% \pm 11.57, U=24.5, p<.01$, significantly greater choice over whether music was heard, $M$ clust $2=24.36 \% \pm 13.24, M$ clust $1=4.35 \% \pm 5.76, U=$ $11.0, p<.01$, significantly greater liking, $M$ clust $2=6.97$ $\pm 0.96, M$ clust $1=4.77 \pm 1.93, U=26.5, p<.01$, and significantly greater attention, $M$ clust $2=5.49 \pm 1.57$, $M$ clust $1=3.41 \pm 1.99, U=42.5, p<.01$, compared with individuals in Cluster $1(n=11)$.

Figure 3 shows how individuals in each cluster were characterized on three summary variables demonstrating the range of reasons, effects, and activities of music reported. Organized by cluster group, Figure 4 shows the overall frequency with which each of the different reasons, effects, and activities were reported. The average number of unique reasons for listening (when chosen), effects of listening (when not chosen), and listening activities that each individual circled served as a summary measure of the degree to which they engaged emotionally with music they heard and the breadth of situations in which they heard it. Mann-Whitney $U$ tests, with adjusted alpha levels of .017 per test $(.05 / 3)$, revealed significant differences between the individuals in the two clusters on all three variables. Individuals in Cluster $1(n=11)$ reported significantly fewer unique reasons and effects of listening compared to individuals 

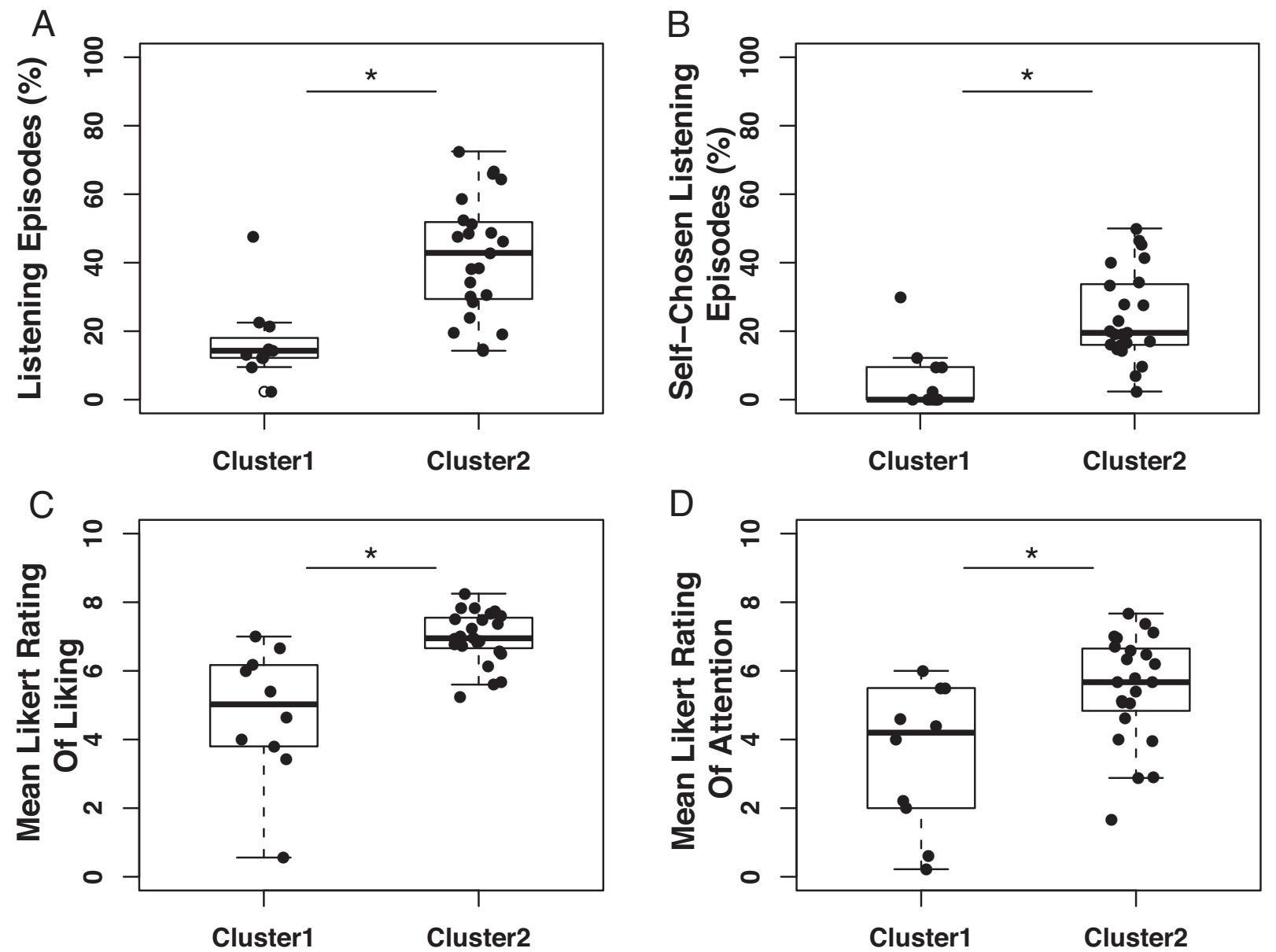

FIGURE 2. Boxplots showing performance on four key variables of interest for participants in Clusters 1 and 2: the percentage of episodes in which music was heard by listeners (A), the percentage of episodes in which listeners had chosen to hear music (B), the mean liking rating across all episodes reported by each listener (C), and the mean attention rating across all episodes reported by each listener (D). The asterisk * denotes significance at $p<.0125$ (Bonferroni corrected).

in Cluster $2(n=23)$ : Reasons: $M$ clust1 $=1.18 \pm 1.66$, $M$ clust $2=3.87 \pm 1.89, U=34.5, p<.01$; Effects: $M$ clust $1=1.73 \pm 1.74, M$ clust $2=4.09 \pm 2.35, U=46.0$, $p<.01$. The effects that individuals in Cluster 1 did report tended to be negative: of the four most common effects of music (when not chosen) for individuals in Cluster 1, three of these were negative: "it negatively changed my mood," "it hindered my concentration," and "it created the wrong atmosphere." For individuals in Cluster 2, the four most common effects were uniformly positive: "it positively changed my mood," "it helped create the right atmosphere, relaxation," and "it matched my mood" (see Figure 4). Further, individuals in Cluster 1 reported significantly fewer unique activities compared to individuals in Cluster 2, $M$ clust $1=2.09 \pm 1.30, M$ clust2 $=4.96 \pm 1.80, U=43.0, p<.01$, with the former failing to incorporate music listening into common everyday activities including getting dressed, bathing, reading, and studying. Also shown in Figure 4 is the overall frequency with which each cluster reported hearing music in the presence of different company types. While the pattern of reports were highly similar across clusters, an interesting observation is that individuals in Cluster 1 did not report hearing music in the presence of friends to the same extent as individuals in Cluster 2.

The previous analysis reveals that individuals in Cluster 1 showed reduced engagement with and appreciation of music in everyday life compared to individuals in Cluster 2. Since all but one of the control participants were in Cluster 2, this cluster may be taken to represent the listening profile typical of the normal population. The inclusion of a sizeable subgroup of amusic individuals in this group motivates a comparison of the listening profiles of these individuals with both 
A

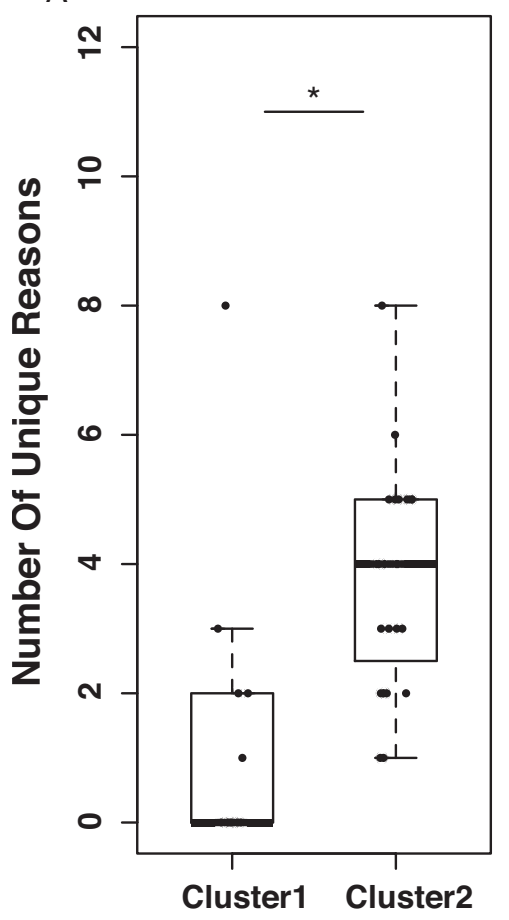

B

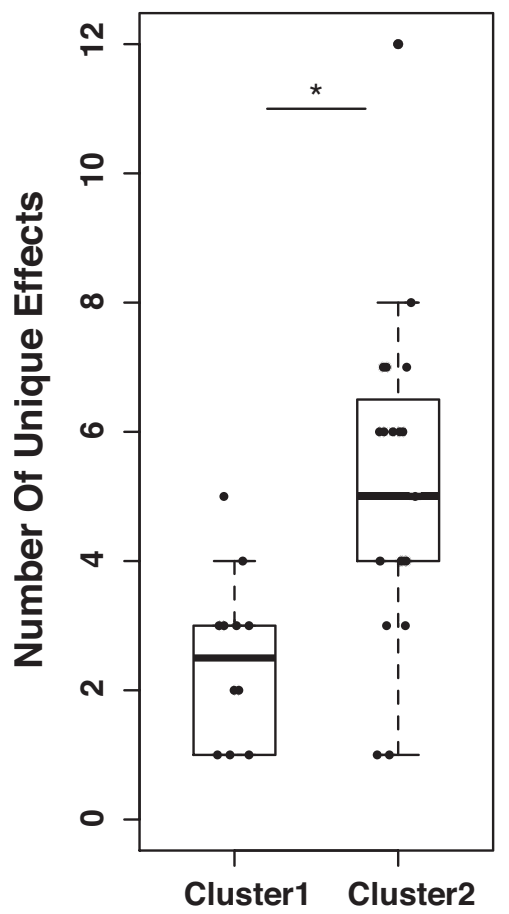

C

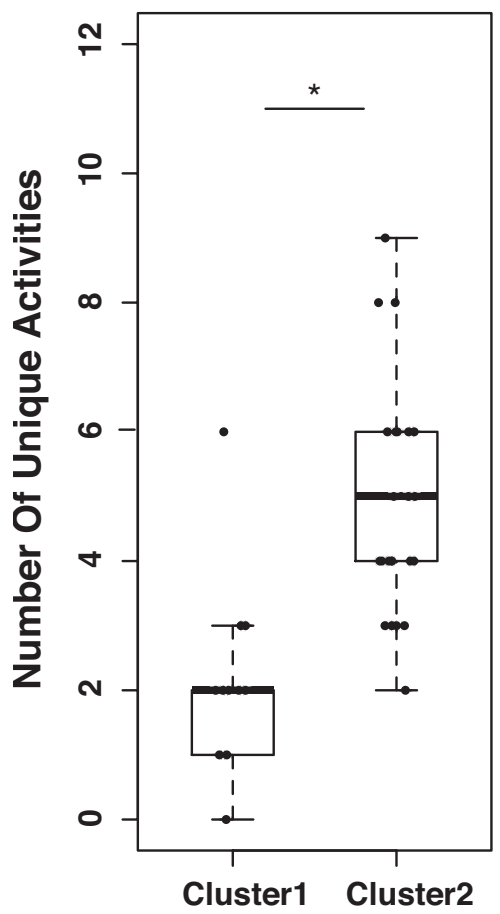

FIGURE 3. Boxplots showing performance on summary variables for participants in Cluster 1 and 2: number of unique reasons for listening (A), unique effects of listening (B), and unique activities during which music was heard (C). The asterisk * denotes significance at $p<.017$ (Bonferroni corrected).

the non-amusic individuals within the same cluster as well as the amusic individuals in Cluster 1 . Thus, as with the comparison between Clusters 1 and 2, the following analysis characterized the amusic and control subgroups in terms of their performance on key and summary variables that described levels of music engagement and appreciation.

\section{AMUSIC SUBGROUP COMPARISONS: PERFORMANCE ON KEY AND SUMMARY VARIABLES}

Figure 5 shows how the three different groups: amusic individuals in Cluster 1 (clust1A, $n=10$ ), amusic individuals in Cluster 2 (clust2A, $n=7$ ), and control individuals in Cluster 2 (clust2C, $n=16$ ) differed on the four key variables. Kruskal-Wallis tests demonstrated an unequal profile on all four key variables across the three groups: Music heard: $H(2)=17.26, p<.01$; Music chosen: $H(2)=20.99, p<.01$ : Liking: $H(2)=13.60, p<.01$, Attention: $H(2)=8.41, p=.02$.

Follow up posthoc Mann-Whitney $U$ tests using a Bonferroni adjusted level of .025 (.05/2) were conducted for each key variable to test whether Cluster 2 amusics differed either in comparison with the Cluster 2 controls with whom they shared a cluster and/or in comparison with the other amusics in Cluster 1 . The former group of tests confirmed that amusic individuals in Cluster 2 were not significantly different from control individuals in the same cluster in terms of how frequently they heard music, $M$ clust2A $=37.38 \% \pm 17.72, M$ clust2C $=43.44 \% \pm$ $17.45, U=44.0, p=.45$, how frequently they chose to listen to music, $M$ clust $2 \mathrm{~A}=17.02 \pm 15.64, M$ clust $2 \mathrm{C}=27.58 \pm$ $11.10, U=23.5, p=.03$, reported liking for the music they heard, $M$ clust $2 \mathrm{~A}=6.48 \pm 0.78, M$ clust $2 \mathrm{C}=7.18 \pm 0.69$, $U=26.0, p=.05$, and reported attention to the music, $M$ clust $2 \mathrm{~A}=5.02 \pm 2.08, M$ clust $2 \mathrm{C}=5.69 \pm 1.33, U=46.0$, $p=.52$. The comparisons between amusic individuals in Cluster 1 and amusic individuals in Cluster 2 revealed that amusic individuals in Cluster 1 heard music more frequently, $M$ clust1A $=13.66 \% \pm 5.67, U=6.0, p<.01$, and had chosen to listen to music more frequently, $M$ clust1A $=3.36 \% \pm 4.97, U=7.5, p<.01$, although the two groups failed to show significant differences in the levels of liking and attention reported, Liking: $U=48.0, p=.09$; Attention: $U=47.0, p=.11$.

Figure 6 illustrates how the three different groups differed on summary variables. Once again Kruskal-Wallis tests revealed significant differences across clusters, Reasons: $H(2)=17.88, p<.01$; Effects: $H(2)=16.39$, 
A

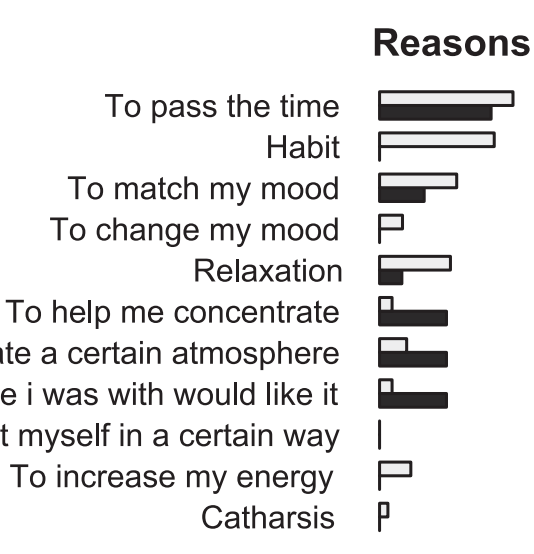

C

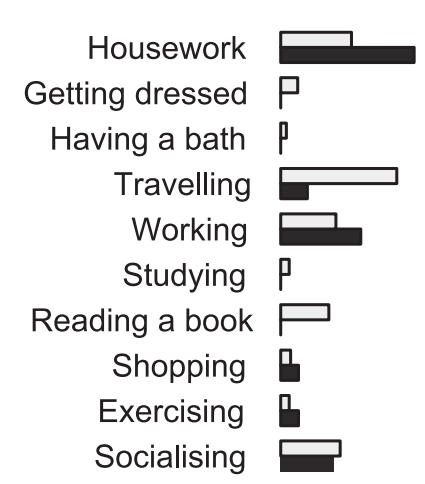

B

Effects

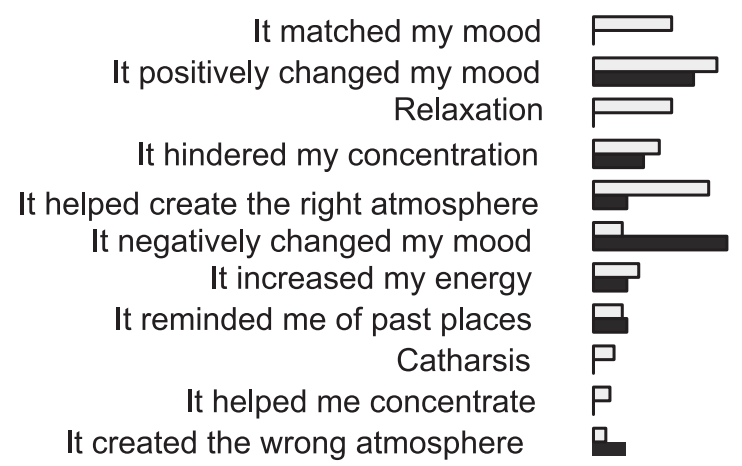

D

\section{Company}

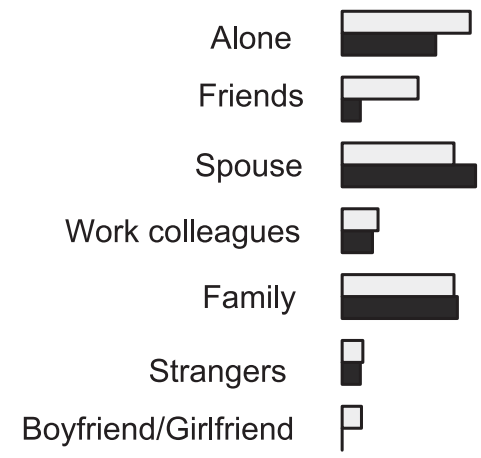

\section{Cluster 1 Cluster 2}

FIGURE 4. List of reasons (A), effects (B) and activities (C) reported by members of Cluster 1 (black) and Cluster 2 (grey) as well company types in which music was heard (D). The length of the bars indicate the relative frequency with which each reason, activity, effect and company type was selected, scaled as a proportion of number of episodes in which music was chosen, the number of episodes in which it was imposed, and number of episodes in which it was heard (for activities and company type), respectively.

$p<.01$; Activities: $H(2)=18.17, p<.01$. Follow up posthoc Mann-Whitney $U$ tests using a Bonferroni adjusted level of $.025(0.05 / 2)$ revealed that amusic individuals in Cluster 2 were not significantly different from the control individuals in Cluster 2 on the number of unique reasons, $M$ clust2A $=3.00 \pm 2.38, M$ clust $2 \mathrm{C}=4.25 \pm 1.57, U=85.0, p=.05$, unique effects, $M$ clust $2 \mathrm{~A}=4.14 \pm 1.57, M$ clust $2 \mathrm{C}=4.06$ $\pm 2.67, U=52.0, p=.81$, and unique listening activities reported, $M$ clust $2 \mathrm{~A}=5.29 \pm 1.60, M$ clust $2 \mathrm{C}=4.81 \pm 1.91$, $U=45.5, p=.50$, while in contrast, they were significantly different from amusics in Cluster 1 in these three respects, Reasons: $M$ clust $1 \mathrm{~A}=0.80 \pm 2.38, U=11.5, p=.02$, Effects: $M$ clust $1 \mathrm{~A}=1.30 \pm 1.06, U=4.0, p<.01$, Activities: $M$ clust1A $=1.80 \pm 0.92, U=1.0, p<.01$.
The range of reasons, effects, and activities reported by the amusic subgroups (clust1A and clust2A) were very similar to those shown by the original clusters which they shared with control participants (Cluster 1 and Cluster 2). While amusics in Cluster 2 reported listening to music for reasons like "relaxation," "to increase energy." and "catharsis," amusics in Cluster 1 did not report using music for reasons related to arousal. In contrast, amusics in Cluster 1 unlike amusics in Cluster 2, reported listening to music because of others "I knew those I was with would like it" and also reported using it "to create a certain atmosphere" to a greater extent than Cluster 2 amusics. For amusics in Cluster 1, the most commonly reported effect was "it negatively changed my mood," where for 
A

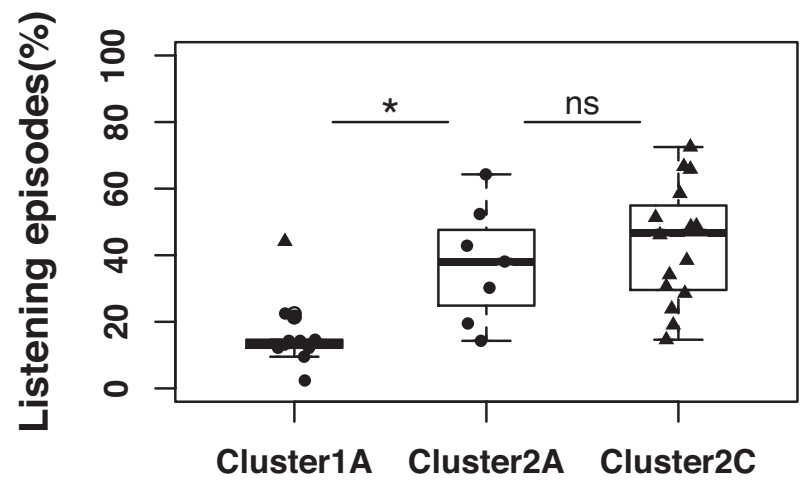

C

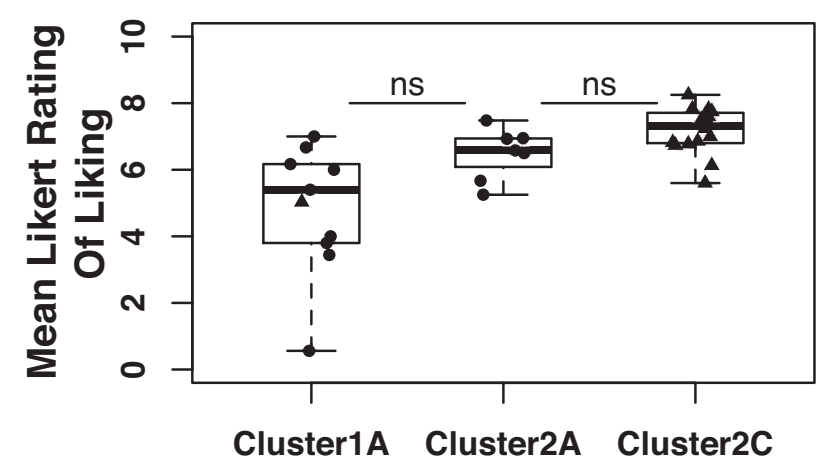

B

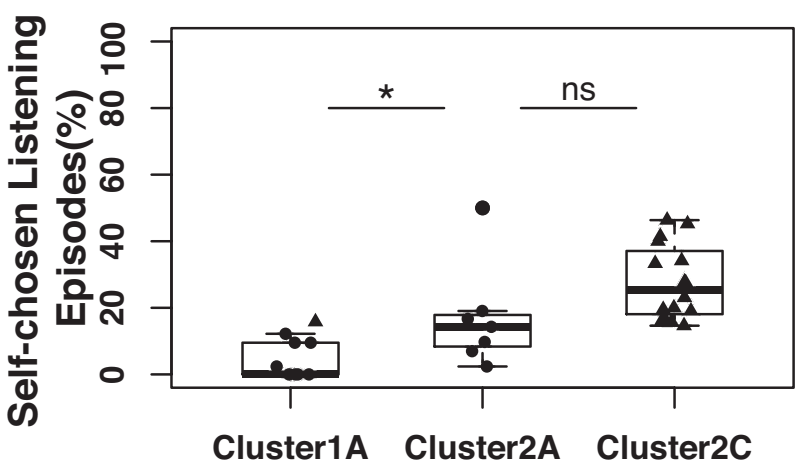

$\mathrm{D}$

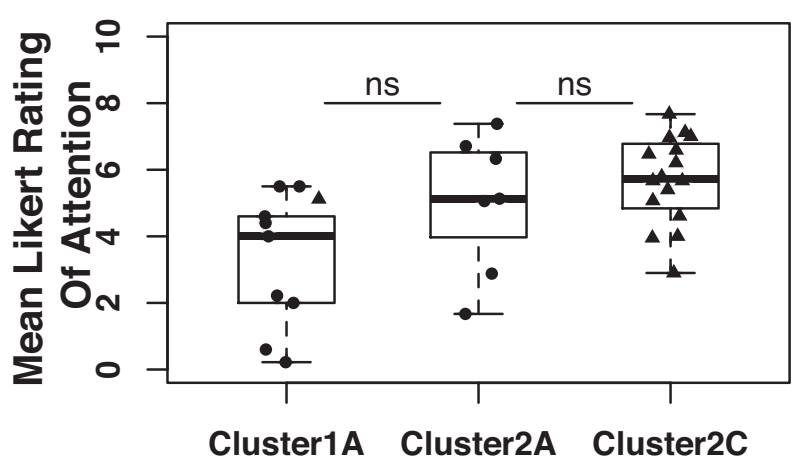

FIGURE 5. Boxplots showing performance on four key variables of interest for the two amusic subgroups and controls in Cluster 2: the percentage of episodes in which music was heard by listeners (A), the percentage of episodes in which listeners had chosen to hear music (B), the mean liking rating across all episodes reported by each listener $(C)$, and the mean attention rating across all episodes reported by each listener (D). Individual data points for the amusic participants are shown using circles while those for controls are shown using triangles. Note that the data of the single control in Cluster 1 is shown as a single triangle in the Cluster $1 \mathrm{~A}$ boxplots but is not included in this group in the statistical comparisons reported in the results section. The asterisk * and ns denote significance and nonsignificance, respectively, at $p<.025$ (Bonferroni corrected).

amusics in Cluster 2, this was "it positively changed my mood." Of the top five effects reported, only two were positive for amusics in Cluster 1 while for amusics in Cluster 2, all but one were positive. Finally, amusics in Cluster 1 failed to incorporate music listening into solitary activities such as bathing, studying, reading a book and exercising where amusics in Cluster 2 reliably did so.

INFLUENCE OF CHOICE AND COMPANY ON LIKING AND ATTENTION Further analysis sought to evaluate whether the three groups differed in the extent to which there was an effect of choice on liking and attention ratings. Wilcoxon signed rank tests using an adjusted alpha level of 0.017 $(0.05 / 3)$ revealed that both controls and Cluster 2 amusic individuals reported significantly greater liking for music that was self chosen as opposed to music that was imposed upon them: For example, music heard while in a public place, clust2C: $M$ chosen $=7.75 \pm 0.88, M$ not chosen $=6.14 \pm 0.14, W=105.0, N=16, p<.01$; clust $2 \mathrm{~A}$ :
$M$ chosen $=7.46 \pm 1.28, M$ not chosen $=5.56 \pm 0.76$, $W=28.0, N=7, p=.02$. In contrast, no modulating effect of choice was seen in the liking ratings of Cluster 1 amusics, $M$ chosen $=6.33 \pm 0.70, M$ not chosen $=4.72 \pm$ 2.24, $W=1.0, N=10, \mathrm{p}>.99$. All three groups reported paying greater attention when they had chosen the music but attention ratings were significantly modulated by choice only in controls, $M$ chosen $=6.21 \pm 1.44, M$ not chosen $=4.86 \pm 1.50, W=82.0, N=16, p=.01$.

There was no difference between the three groups in how likely they were to be listening alone versus in company, $M$ clust $1 \mathrm{~A}=33.5 \% \pm 27.38, M$ clust $2 \mathrm{~A}=$ $33.74 \% \pm 24.4, M$ clust2C $=45.12 \% \pm 23.88, H(2)=$ $1.78, p=.41$. Further analysis was conducted to evaluate whether the presence of others had an influence on liking and attention ratings as reported by any of the three groups. Wilcoxon signed rank tests using an adjusted alpha level of $0.017(0.05 / 3)$ revealed that liking and attention ratings were significantly higher for control 
A

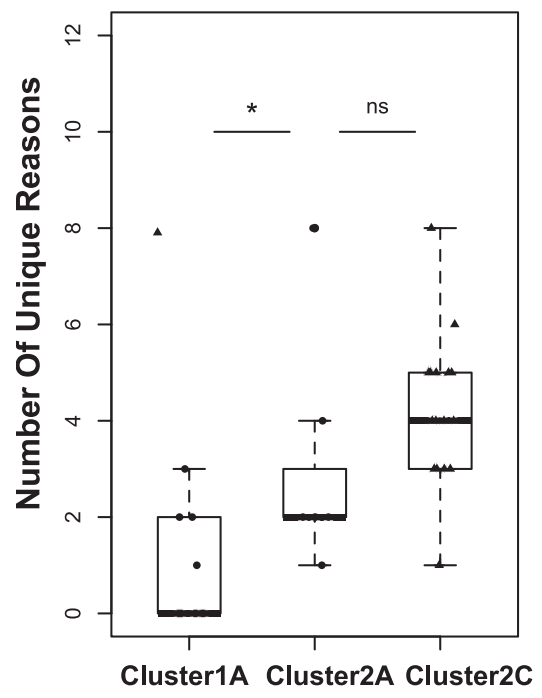

B

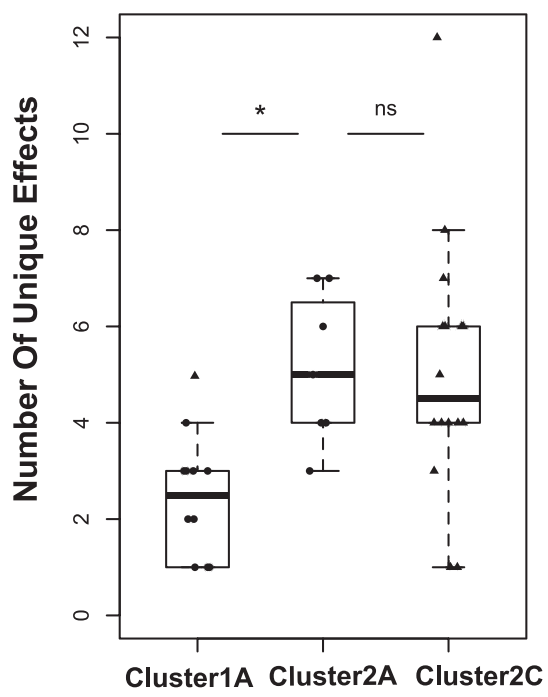

C

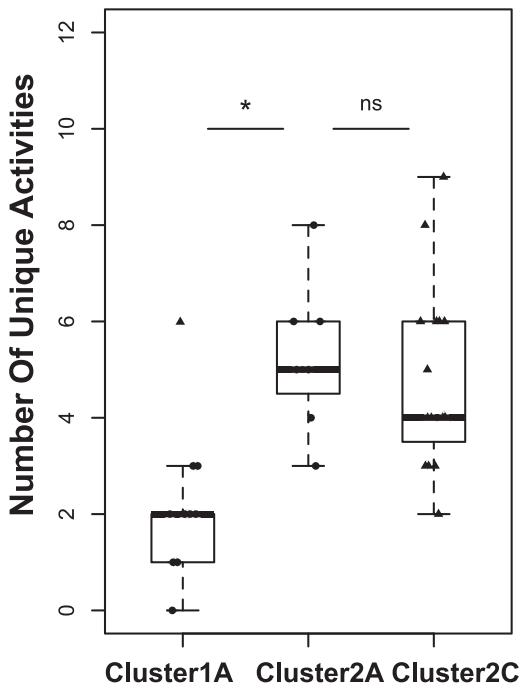

FIGURE 6. Boxplots showing performance on summary variables for the two amusic subgroups and controls in Cluster 2: number of unique reasons for listening (A), unique effects of listening (B), and unique activities during which music was heard (C). Individual data points for the amusic participants are shown using circles while those for controls are shown using triangles. Note that the data of the single control in Cluster 1 is shown as a single triangle in the Cluster $1 \mathrm{~A}$ boxplots but is not included in this group in the statistical comparisons reported in the results section. The asterisk * denotes significance at $p<.025$ (Bonferroni corrected).

participants when music was heard alone than in company, Liking: $W=108.0, N=16, p<.01$, Attention: $W=107.0, N=16, p<.01$. However, neither of the amusic groups showed this effect: in both cases, liking and attention ratings were not significantly modulated by the presence or absence of others.

In summary, amusic individuals in Cluster 1 demonstrated significantly lower levels of music appreciation and engagement than Cluster 2 individuals on a number of key variables. In contrast, amusic individuals in Cluster 2 showed only slight evidence of differing from the controls with whom they shared a cluster, suggesting that these amusic individuals possess broadly typical levels of music engagement and appreciation.

\section{MUSIC STYLES}

Analysis sought to investigate whether there were any differences between clusters and amusic subgroups in the types of music that was heard. No difference was found between clusters ( $\mathrm{n}$ clust $1=11, \mathrm{n}$ clust $2=23$ ) in terms of the frequency with which music with lyrics was heard, $M$ clust $1=52.80 \pm 0.23, M$ clust $2=74.10 \pm$ $0.44, U=88.5, p=.31$. Nor was there a difference between the amusic subgroups ( $\mathrm{n}$ clust $1 \mathrm{~A}=10, \mathrm{n}$ clust $2 \mathrm{~A}$ $=7)$ in this respect, $M$ clust1A $=50.90 \pm 0.46, M$ clust $2 \mathrm{~A}=72.60 \pm 0.22, U=24.5, p=.49)$. With regard to styles of music heard, pop music was the most commonly reported in both clusters (Cluster $1=50 \%$,
Cluster $2=34.5 \%)$ followed by folk (16.7\%) and golden oldies (14.8\%) in Cluster 1 individuals, and classical (14.2\%) and rock (13.4\%) music in Cluster 2 individuals. For amusic individuals in Cluster 1, the most frequently reported genres were pop (45.5\%) and golden oldies (15.2\%) while in Cluster 2, they were pop (37.60\%) jazz (12.9\%) and rock music (9.9\%).

RELATIONSHIP WITH MBEA AND DEMOGRAPHIC FACTORS

Given the evidence for distinct subgroups of amusic individuals, further analysis sought to identify factors that might differentiate amusic individuals displaying low versus typical levels of engagement with music. Figure 7 plots the MBEA scores and demographics of the two amusic subgroups ( $\mathrm{n}$ clust $1 \mathrm{~A}=10$, $\mathrm{n}$ clust $2 \mathrm{~A}=7$ ). Neither performance on the pitch-based subtests of the MBEA [Scale: $M$ clust1A $=18.90 \pm 3.18, M$ clust $2 \mathrm{~A}=19.86 \pm 1.95, U=26.0, p=.40$; Contour: $M$ clust1A $=18.90 \pm 3.73, M$ clust $2 \mathrm{~A}=21.57 \pm$ 2.23, $U=21.0, p=.19$; Interval: $M$ clust1A $=17.70 \pm 2.63$, $M$ clust $2 \mathrm{~A}=19.00 \pm 2.16, U=22.0, p=.22$; Pitch composite: $M$ clust $1 \mathrm{~A}=55.50 \pm 7.58, M$ clust $2 \mathrm{~A}=60.43 \pm 3.26, U=$ $22.0, p=.32]$ nor performance on the rhythm subtest $[M$ clust1A $=23.50 \pm 4.62, M$ clust2A $=23.57 \pm 2.23, U=35.0$, $p>.99$ ] could account for the difference between the amusic subgroups. There were also no differences in the mean age of the two groups, $M$ clust1A $=49.10 \pm 11.45, M$ clust2A $=40.71 \pm 12.02, U=50.0, p=.16$, their years of education, $M$ clust1 $\mathrm{A}=16.56 \pm 2.55, M$ clust $2 \mathrm{~A}=14.71 \pm$ 
A
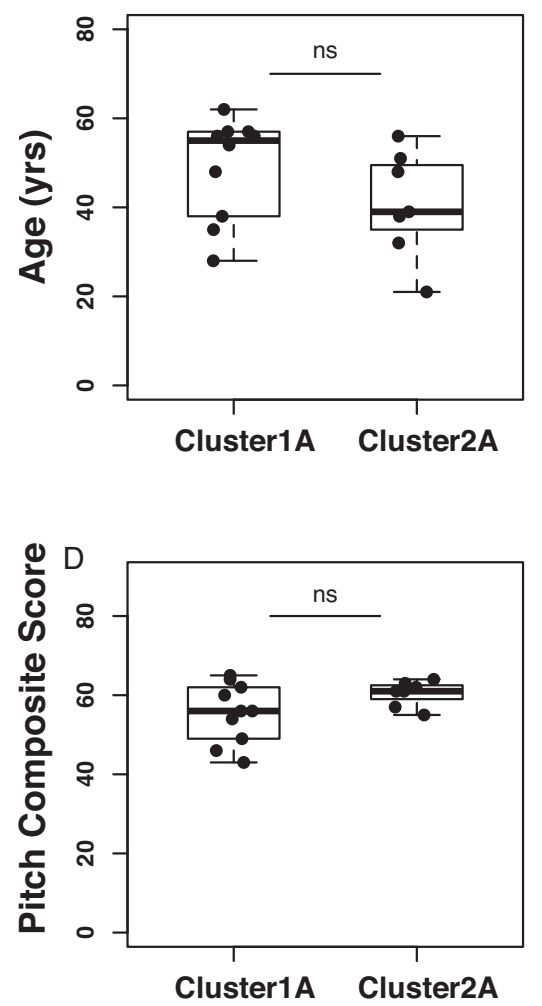

B
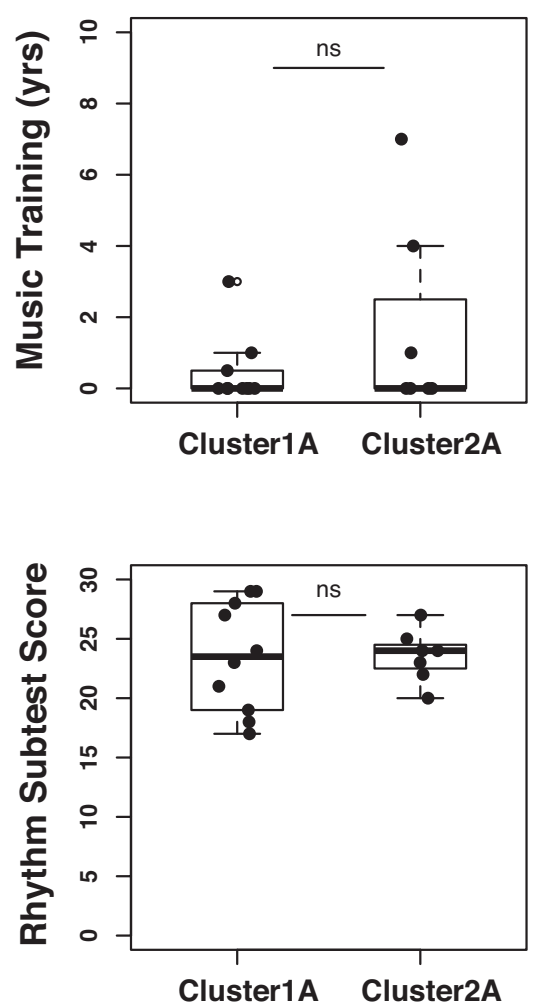

C

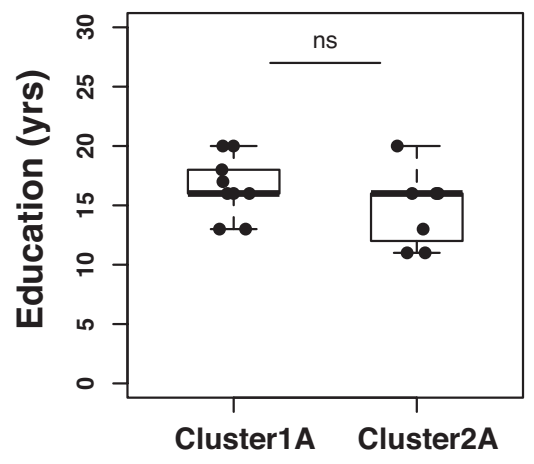

FIGURE 7. Boxplots showing how amusic subgroups differed on age (A), years of music training (B), years of education (C), MBEA pitch composite score (D), and MBEA rhythm subtest score (E). The ns denotes nonsignificance at $p<.05$.

$3.25, U=43.5, p=.21$, or their gender, clust1A: 2 male, 8 female; clust2A: 3 male, 4 female; $\chi(1)=1.04, p=.31$. Furthermore, there was no difference in the years of music training reported by the two subgroups, $M$ clust1A $=0.45 \pm$ $0.96, M$ clust $2 \mathrm{~A}=1.71 \pm 2.75, U=27.5, p=.42$. A chisquare analysis revealed that any difference in the way those individuals with at least some music training were distributed over the two amusic subgroups was simply due to chance, $c(1)=0.30, p=.59$, and an additional cluster analysis including only those participants with no music training experience (11 amusics, 10 controls) produced largely similar results. Thus, in terms of the MBEA and demographic variables the two amusic subgroups from Cluster 1 and 2 appeared to be indistinguishable.

\section{Discussion}

Individuals with congenital amusia have a genuine perceptual agnosia; they fail to recognize the tunes that most people could easily identify and have difficulty discriminating melodies without the aid of lyrics.
While most research has focused on the perceptual deficits that underlie these difficulties, the present study aimed to determine what impact these perceptual deficits have on the uses, functions and effects of music in everyday life as well as the levels of liking and attention reported when music is heard.

An experience sampling approach was used to gather information about music listening behavior and appreciation in individuals with amusia and matched controls. This method allows researchers to probe experiences "in the moment” (Larson \& Csikszentmihalyi, 1983), providing a level of ecological validity that is lacking from retrospective reports. In the context of the present study, this approach provided an objective measure of the degree to which individuals with amusia are exposed to music in everyday life as well as the extent to which they voluntarily choose to hear it. In addition, it allowed the collection of nuanced information on individuals' motivations for and effects of listening and permitted evaluation of the roles of contextual and social factors on music listening behavior and appreciation. 
The detailed and multifaceted nature of the data provided by ESM necessitated the use of multivariate statistical techniques that allowed us to consider patterns of behavior (music listening profiles) rather than performance on individual items. Hierarchical cluster analysis highlighted similarities in music listening profiles in a data driven way. This statistical approach is blind to the status of an individual as amusic or control. Clusters were formed purely on the basis of the similarity of profiles. This feature of the analysis presented an interesting possibility to determine to what degree the real world musical listening behavior of amusics was similar or different to controls.

At least two possibilities were envisaged regarding the extent to which individuals with amusia would be found to show typical levels of engagement with music in everyday life. One view, based on the premise that engagement with and appreciation of music depends upon having intact perceptual processing, would predict that amusics and controls would form largely independent clusters, with amusic individuals exhibiting little evidence of engaging with or appreciating music and control individuals showing high levels of both. In contrast, another view, based on ethnographic, psychological and sociological research, would propose that music's extrinsic properties afford a sufficient number of reasons for amusic individuals to choose to engage with and appreciate music in their everyday lives even if listeners are limited in the extent to which they can perceive it. This latter view would suggest that amusics, if probed, would be largely indistinguishable from controls in respect to everyday music listening habits.

In fact, the results of analysis yielded a more nuanced picture: a two-cluster solution, with $59 \%$ of the amusic sample and $6 \%$ of controls in one cluster and $41 \%$ of the amusic sample and $94 \%$ of controls in the second cluster. Thus, while the majority of individuals with amusia showed profiles that were dissimilar to controls, a sizeable subgroup showed profiles that were largely similar to controls. This finding is consistent with previous work (McDonald \& Stewart, 2008) as well as with anecdotal reports presenting a mixed picture of how individuals with amusia feel about music, with some claiming music sounds like "banging" and "noise" and others reporting deriving considerable pleasure from it (Stewart, 2006, 2008). The current findings also builds on previous ones, by showing that critical factors which define and differentiate these distinct amusic subgroups include the extent to which individuals voluntarily expose themselves to music and incorporate it into a range of everyday activities to achieve a range of psychological states.

As with previous attempts, it was difficult to attribute the heterogeneity in music appreciation seen in the amusic sample to differing levels of perceptual ability. In particular, there was no support for the view that amusic individuals showing typical levels of engagement simply have a less severe case of amusia. Neither the performance on any of the MBEA pitch subtests, nor performance on the rhythm subtest could account for the differences in appreciation found between the groups. It was also difficult to account for these differences in terms of demographic factors. McDonald and Stewart (2008) reported a significant relationship between age and levels of engagement, such that younger amusic individuals reported greater engagement than older amusic individuals. However, the current study failed to replicate this effect and we were unable to account for the differences observed in the amusic subgroups with respect to years of music training.

Given that differences in perceptual abilities could not account for the differences seen between the two groups in terms of musical engagement, it becomes important to consider whether music's extrinsic properties may play a significant role in explaining these differences. Indeed a number of factors may result in individual differences in music appreciation demonstrated by amusic individuals with similarly impaired music perception. Music is a highly prized part of many important social and cultural events and there may be some individuals for whom full participation in such events is of paramount importance. Such individuals might, regardless of their power to perceive it fully, willingly choose to immerse themselves in musical environments. Further, personality types have been shown to predict musical preferences (Rentfrow \& Gosling, 2003) and it is possible that sensation seeking individuals who are keen to extract enjoyment out of as many daily activities as possible will choose to engage with music despite an impaired ability to perceive it relative to normal listeners. In addition to individual differences in personality, differences in individuals' lifestyles may lead to differences in the contexts in which they experience music. It is plausible that those individuals having greater exposure to music in the presence of friends and family would have built up more positive associations with music than those individuals whose musical experiences are limited to contexts deemed less enjoyable in general (e.g., imposed music in public places).

However, while social and cultural aspects of music are important factors to consider when it comes to understanding engagement and appreciation of music, perceptual abilities tested here were not exhaustive, leaving open the possibility that the currently observed differences between the amusic subgroups in terms of musical engagement may relate specifically to these additional (untested) perceptual factors. The first of these concerns is the implicit processing of musical structure. An increasing amount of literature suggests that while individuals with congenital amusia are impaired in tasks (such as the MBEA) where explicit responses (e.g., same/different judgments) are required, 
they show comparable performance to controls when their knowledge is probed using implicit methods. Critically, such implicit knowledge of musical structure may allow individuals with amusia to build pitch expectations as they listen to music, an activity which is proposed to be a rich source of music appreciation (Huron, 2006). Evidence for implicit music processing in amusic individuals comes from fMRI and EEG studies demonstrating that individuals with amusia process sub-threshold pitch deviations and out-of-tune notes inserted in melodies below the level of conscious awareness (Braun et al., 2008; Hyde, Zatorre, \& Peretz, 2010; Peretz, Brattico, Jarvenpaa, \& Tervaniemi, 2009). In addition, Tillmann and colleagues (2009) report the presence of a harmonic priming effect in a group of individuals with congenital amusia (unpublished data), and a recent study from our group demonstrated that amusic individuals possess the learning mechanisms required to internalize the regularities in novel tonal materials even when they contain small pitch intervals (Omigie \& Stewart, 2011). The observed differences in the extent to which amusic individuals show musical engagement in the current study may therefore be due to individual differences in the extent to which they have acquired knowledge of musical structure over a lifetime of exposure. Evidence for a possible dissociation between perception and emotional response to music has also been seen in clinical cases where some individuals still derive pleasure from music despite impaired music perception (Peretz, Cagnon, \& Bouchard, 1998) and others report losing the intense emotional responses to music they formerly had (Gosselin et al., 2005; Griffiths, Warren, Dean \& Howard, 2004).

In addition to differences in the extent to which amusics choose to or are able to implement their knowledge of the pitch based aspects of music at an implicit level, there may also be differences in the extent to which rhythmic cues are processed in the low versus typically engaged amusic subgroups. While no difference was seen across groups in performance on the MBEA rhythm subtest, this subtest provides only a partial indication of the degree to which rhythmic processing may be intact, and the current findings allow for the possibility that those amusic individuals who showed typical music engagement were engaging with the rhythmic dimension of the music to a greater extent than those who did not. The finding that the amusic subgroup displaying typical levels of engagement reported using music for reasons such as "relaxation" and "to increase my energy" while the non-appreciating subgroup did not, suggests that the former subgroup may be using the rhythmic and temporal aspects of music to modulate arousal. The additional finding that jazz music was the second most popular genre after pop music in these individuals is also worth noting. Further evidence that rhythm may provide a sufficient and rich source of musical appreciation comes from some cochlear implantees who, despite having a coarse perception of pitch, report enjoying listening to music, most likely owing to their normal ability to hear rhythm and tone duration. These reports of enjoyment are most common among patients who are born deaf and have never experienced melodic pitch patterns (Lassaletta et al., 2007; Drennan \& Rubinstein, 2008).

Finally, notwithstanding the need to investigate whether differences in implicit processing of pitch, harmony and rhythm are the source of the contrasting attitudes to music seen here in our amusic sample, future studies using the current methodology could be improved in at least two respects. First, a larger sample size would allow a more thorough investigation (as was permitted in the study of North and colleagues (2004) into how reasons and effects of listening are contingent on concurrent activities and company types present, with such analyses having the potential to present a clearer picture regarding the influence of contextual factors on motivations and listening habits. Secondly, while the current study did not require any further detail on contact episodes where no music was heard, a future study collecting data on contextual factors in such situations would allow a better characterization of individuals' listening habits specifically as they relate to their individual lifestyles and the degree of musical listening afforded.

\section{Conclusions}

The current study, exploring the everyday uses, effects, and functions of music in individuals with amusia, reveals that a difficulty in melody recognition and discrimination does not necessarily result in a lack of musical appreciation: a sizeable subgroup of the amusic sample showed levels of musical engagement and appreciation that were similar to controls in many respects. Performance on the MBEA pitch-based or rhythm subtests could not account for the differences between those amusic subgroups showing low versus typical levels of engagement. Demographic factors such as the age of listeners or their years of music training could not account for the difference between amusic subgroups as well. Possible reasons for this heterogeneity, in the extent to which amusics engage with music, may be explained by socio-cultural factors and/or differing levels of implicit musical knowledge. Future studies that encompass a thorough characterization of amusic individuals in terms of their personality types, lifestyle differences, and degree of implicit musical knowledge should lead to a better understanding of the relative importance of each of these factors in facilitating 
musical engagement, even in the face of striking musical perceptual deficits.

\section{Author Note}

This study was supported by a grant to Lauren Stewart from the Economic and Social Research Council (ESRC) and a joint studentship awarded to Diana Omigie by the ESRC and the Medical Research Council (MRC).
We would like to thank all the participants for their continued assistance in our studies of amusia, and for their insights. In addition, we are grateful to Richard Jebb who contributed to the data collection.

Correspondence concerning this article should be addressed to Diana Omigie, Department of Psychology, Whitehead building, Goldsmiths, University of London, New Cross, London, SE14 6NW, United Kingdom E-MAIL: d.omigie@gold.ac.uk

\section{References}

AlLEN, G. (1878). Note deafness. Mind, 10, 157-167.

Ayotte, J., Peretz, I., \& Hyde, K. (2002). Congenital amusia - A group study of adults afflicted with a music-specific disorder. Brain, 125, 238-251.

Braun, A., McArdle, J., Jones, J., Nechaev, V., Zalewski, C., Brewer, C., \& Drayna, D. (2008). Tune deafness: Processing melodic errors outside of conscious awareness as reflected by components of the auditory ERP. PloS One, 3, 1-6.

DeNora, T. (2000). Music in everyday life. Cambridge, UK: Cambridge University Press.

Drayna, D., Manichaikul, A., de Lange, M., Snieder, H., \& SPECtor, T. (2001). Genetic correlates of musical pitch recognition in humans. Science, 291, 1969-1972.

Drennan, W. R., \& Rubinstein, J. T. (2008). Music perception in cochlear implant users and its relationship with psychophysical capabilities. Journal of Rehabilitation Research and Development, 45, 779-789.

EveritT, B. (1974). Cluster analysis. London, UK: Heinemann Educational for the Social Science Research Council.

FIELD, A. (2005). Discovering statistics using SPSS. London, UK: Sage.

Foxton, J. M., Dean, J. L., Gee, R., Peretz, I., \& Griffiths, T. D. (2004). Characterization of deficits in pitch perception underlying 'tone deafness.' Brain 127, 801-810.

Galvin III, J. J., Fu, Q. J., \& Nogaki, G. (2007). Melodic contour identification by cochlear implant listeners. Ear and Hearing, 28, 302-319.

Gfeller, K., WitT, S., Woodworth, G., Mehr, M. A., \& KnUtson, J. (2002). Effects of frequency, instrumental family, and cochlear implant type on timbre recognition and appraisal. Annals of Otology, Rhinology and Laryngology, 111, 349-356.

Gfeller, K., Christ, A., Knutson, J., Witt, S., \& Mehr, M. (2003). The effects of familiarity and complexity on appraisal of complex songs by cochlear implant recipients and normal hearing adults. Journal of Music Therapy, 40, 78-112.

Gosselin, N., Peretz, I., Noulhiane, M., Hasboun, D., Beckett, C., BAUlaC, M., \& SAmson, S. (2005). Impaired recognition of scary music following unilateral temporal lobe excision. Brain, 128, 628-640.
Gosselin, N., Jolicoeur, P., \& Peretz, I. (2009). Impaired memory for pitch in congenital amusia. Annals of the New York Academy of Sciences, 1169, 270-272.

Griffiths, T. D., Warren, J. D., DeAn, J. L., \& Howard, D. (2004). When the feeling's gone: A selective loss of musical emotion. Journal of Neurology, Neurosurgery and Psychiatry, 75, 344-345.

Hays, T., \& Minchiello, V. (2005). The meaning of music in the lives of older people: A qualitative study. Psychology of music. $33,437-451$

Huron, D. (2006). Sweet anticipation: Music and the psychology of expectation. Cambridge, MA: MIT Press.

Hyde, K. L., \& Peretz, I. (2004). Brains that are out of tune but in time. Psychological Science, 15, 356-360.

Hyde, K., Zatorre, R., Griffiths, T., Lerch, J., \& Peretz, I. (2006). Morphometry of the amusic brain: A two-site study. Brain, 129, 2562-2570.

Hyde, K., Zatorre, R., \& Peretz, I. (2010). Functional MRI evidence of an abnormal neural network for pitch processing in congenital amusia. Cerebral Cortex, 21, 292-299

KonECNI, V. J. (1982). Social interaction and musical preference. In D. Deutsch (Ed.), The psychology of music (pp. 497-516). New York: Academic Press.

LARSON, R., \& Csikszentmihalyi, M. (1983). The experience sampling method. New directions for Methodology of Social and Behavioural Science, 15, 41-56.

Lassaletta, L., Castro, A., Bastarrica, M., Pérez-Mora, R., Madero, R., De Sarriá, J., \& Gavilan, J. (2007). Does music perception have an impact on quality of life following cochlear implantation? Acta Otolaryngologica, 127, 682-686.

Leal, M. C., Shin, Y. J., Laborde, M., Calmels, M., Verges, S., LUGARDON, S., ANDRIEU, S. ET AL. (2003). Music perception in adult cochlear implant recipients. Acta Oto-Laryngologica, 123, 826-835.

LouI, P., Alsop, D., \& SchlaUg, G. (2009). Tone-deafness: A disconnection syndrome? Journal of Neuroscience, 29, 10215-10220.

MacDonald, A. R., Hargreaves, D. J., \& Miell, D. (2002). What are musical identities and why are they important? In A. R. MacDonald, D. J. Hargreaves, \& D. Miell (Eds.), Musical identities (pp. 1-6). New York: Oxford University Press. 
Mandell, J., Schulze, K., \& Schlaug, G. (2007). Congenital amusia: An auditory-motor feedback disorder? Restorative Neurology and Neuroscience, 25, 323-34.

McDonald, C., \& Stewart, L. (2008). Uses and functions of music in congenital amusia. Music Perception, 25, 345-355.

North, A. C., \& Hargreaves, D. J. (1999). Music and adolescent identity. Music Education Research, 1, 75-92.

North, A. C., Hargreaves, D. J., \& Hargreaves, J. J. (2004). Uses of music in everyday life. Music Perception, 22, 63-99.

Omigie, D., \& Stewart, L. (2011). Preserved statisitical learning of tonal and linguistic material in individuals with congenital amusia. Frontiers in Psychology, 2, 109.

Peretz, I., Cagnon, L., \& Bouchard, B. (1998). Music and emotion: Perceptual determinants, immediacy and isolation after brain damage. Cognition, 68, 111-141.

Peretz, I., Ayotte, J., Zatorre, R. J., Mehler, J., Ahad, P., Penhune, V. B., \& JuTRAs B. (2002). Congenital amusia: A disorder of fine-grained pitch discrimination. Neuron, 33, 185-191.

PeretZ, I., Champod, A. S., \& Hyde, K. L. (2003). Varieties of musical disorders. The Montreal Battery of Evaluation of Amusia. Annals of the New York Academy of Sciences, 999, 58-75.

Peretz, I., Cummings, S., \& Dubé, M. (2007). The genetics of congenital amusia (tone deafness): A family-aggregation study. American journal of Human Genetics, 81, 582-588.

Peretz, I., Brattico, E., JarvenpaA, M., \& Tervaniemi, M. (2009). The amusic brain: In tune, out of key, and unaware. Brain, 132, 1277-1286.

Rentrrow, P. J., \& Gosling, S. D. (2003). The do, re, mi's of everyday life: The structure and personality correlates of music preferences. Journal of Personality and Social Psychology, 84, 1236-1256.

Russell, P. A. (1997). Musical tastes and society. In D. J. Hargreaves \& A. C. North (Eds), The social psychology of music (pp. 141-158). Oxford, UK: Oxford University Press. Sloboda J. A., O’Neill S. A., \& IVAldi, A. (2001). Functions of music in everyday life: An exploratory study using the Experience Sampling Method. Musicae Scientiae, 5, 9-32.

SMALL, C. (1998). Musicking: The meanings of performing and listening. Middletown, CT: Wesleyan University Press.

Stewart, L. (2006). Congenital amusia. Current Biology, 16, 904-906.

Stewart, L., von Kriegstein, K., Warren, J. D., \& Griffiths, T. D. (2006). Music and the brain: Disorders of musical listening. Brain, 129, 2533-2553.

STEWART, L. (2008). Fractionating the musical mind: Insights from congenital amusia. Current Opinion in Neurobiology, 18, 127-130.

Sucher, C. M., \& McDermott, H. J. (2007). Pitch ranking of complex tones by normally hearing subjects and cochlear implant users. Hearing Research, 230, 80-87.

Tillmann, B., Schulze, K., \& Foxton, J. M. (2009). Congenital amusia: A short-term memory deficit for non-verbal, but not verbal sounds. Brain and Cognition 71, 259- 264

Williamson, V. J., McDonald, C., Deutsch, D., Griffiths, T. D., \& STEWART, L. (2010). Faster decline of pitch memory over time in congenital amusia. Advances in Cognitive Psychology, $6,15-22$.

Zillmann, D., \& GAN, S. (1997). Musical taste in adolescence. In D. J. Hargreaves \& A. C. North (Eds.), The social psychology of music (pp. 161-187). Oxford, UK: Oxford University Press. 
APPENDIX 1: A Sheet From the ESM diary.

Date................... Time when message was received................ Time when questionnaire was filled out.........

Are you listening to any music at the moment, or have you heard any in the past 30 minutes? $\quad$ YES / NO

IF NO THERE IS NO NEED TO CONTINUE.

IF YES PLEASE CONTINUE WITH THE QUESTIONNAIRE

(These questions relate to your most recent listening episode. If you are not currently listening to music but have been in the past $\mathbf{3 0}$ minutes, please cast your mind back to what you are doing and how the music made you feel)

Are you alone?

YES / NO

If no, who are you with? (PLEASE CIRCLE)

friend(s), spouse/partner, work colleague(s), family member(s), stranger(s), boyfriend/girlfriend, other(please specify)

Did you choose to listen to this music yourself?

YES / NO

If yes, why did you choose to listen to this music?

(PLEASE CIRCLE)

to pass the time, habit, to help me concentrate, to match my mood, to change my mood, to create a certain atmosphere, relaxation, I knew those I was with would like it, to present myself in a certain way, increase my energy, catharsis, to remind me of past people and places, other (please specify)

If no, what effect has the music had on you?

(PLEASE CIRCLE)

it matched my mood, positively changed my mood, negatively changed my mood, increased my energy, relaxation, reminded me of past places, catharsis, helped me concentrate, hindered my concentration, helped create the right atmosphere, created the wrong atmosphere, other (please specify)

How would you rate your liking of this music? 0-10 $(0=$ hate it, $10=$ love it $)$

How much attention are you paying to the music? 0-10 ( $0=$ ignoring it, $10=$ attending to it fully $)$

What are you doing whilst listening to this music? (PLEASE CIRCLE)

housework, getting dressed, having a bath, travelling, working, studying, reading a book, shopping, exercising, socialising, other (please specify)

Does the music you are listening to contain lyrics?

YES / NO

What style of music is it?

(PLEASE CIRCLE)

pop, rock, indie, rap/hip hop, dance, heavy metal, punk, blues, golden oldies, classical, jazz, r n' b, gospel, soul, world, folk, country, other (please specify) 